\title{
Northern Goshawk Surveys on BLM Lands within the St. Joe Mountains of Northern Idaho
}

by

Greg S. Draheim, Mary Terra-Berns, Jay F. Shepherd, Katie M. Kuttner,

Jonathan W. Beals, Charles E. Harris and Wayne Melquist

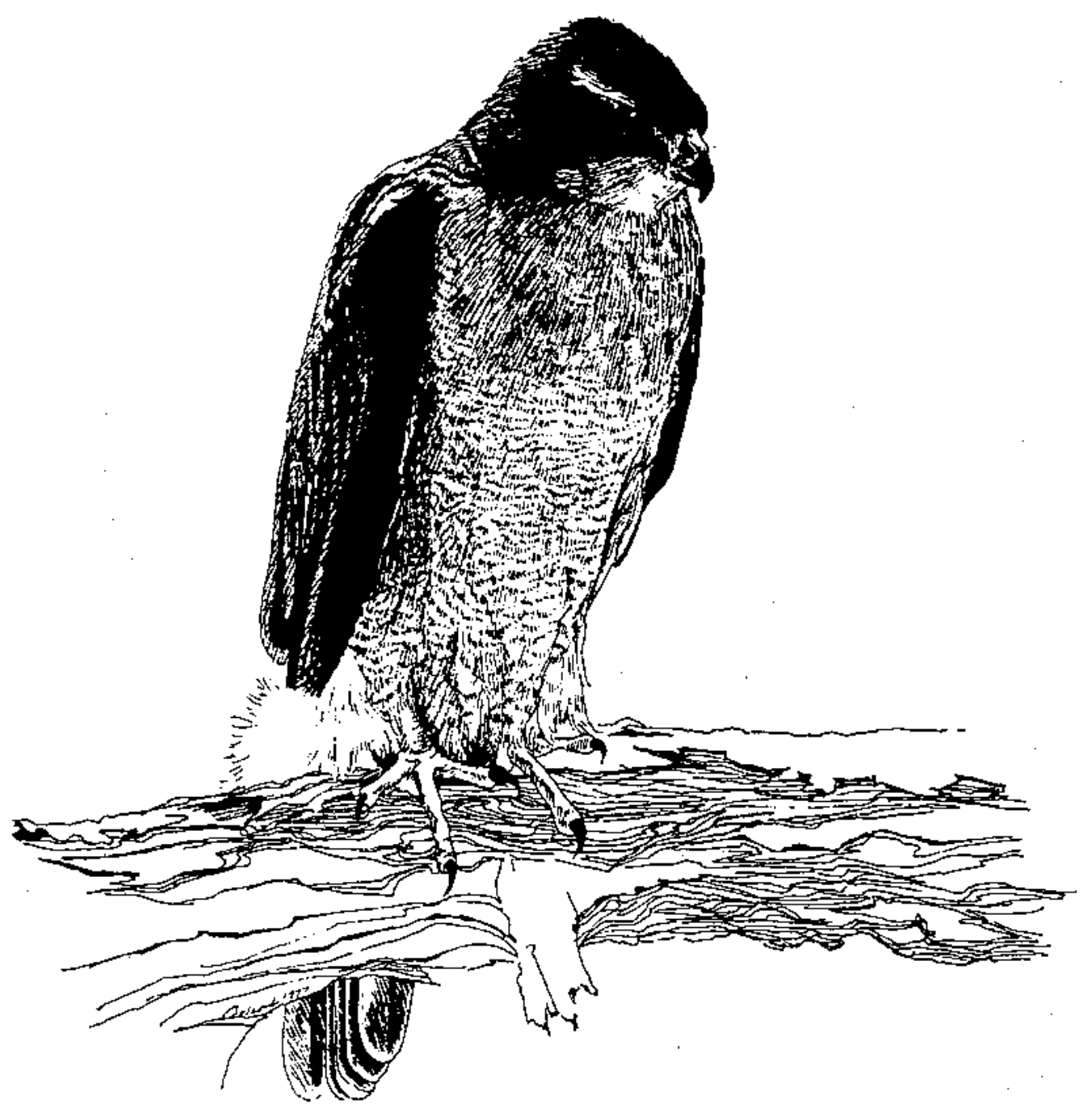


Final Report

\title{
NORTHERN GOSHAWK SURVEYS ON BLM LANDS WITHIN THE ST. JOE MOUNTAINS OF NORTHERN IDAHO
}

\author{
BY \\ Greg S. Draheim, Mary Terra-Berns, Jay F. Shepherd, Katie M. Kuttner, \\ Jonathan W. Beals, Charles E. Harris and Wayne Melquist \\ Nongame and Endangered Wildlife Program \\ Bureau of Wildlife
}

August 1998

Idaho Department of Fish and Game

600 S. Walnut, P.O. Box 25

Boise, Idaho 83707

Stephen P. Mealey / Director

Challenge Cost-Share Project

\#I422-D910-A5-0202

Idaho Department of Fish and Game

Bureau of Land Management,

Upper Columhia and Salmon-Clearwater District 


\begin{abstract}
A cooperative project between the Department of the Interior, Bureau of Land Management (BLM) and the Idaho Department of Fish and Game was conducted to determine the presence or absence of the Northern Goshawk (Accipiter gentilis) on BLM lands in northern Idaho. Responses to taped broadcasts of the adult "alarm" and juvenile "wail" calls were recorded. Two hundred thirty-eight calling stations were surveyed between 6 June 1994 and 1 August 1994. Fourteen responses at 8 different calling stations were elicited. Three hundred forty-three calling stations were surveyed between 8 June 1995 and 14 August 1995. Four responses were recorded at 3 different stations. In 1996, 274 calling stations were surveyed between 6 June and 2 August. One response was recorded during the fledgling period. One hundred sixty-eight calling stations were surveyed between 4 June 1998 and 6 August 1998. One response was recorded during the nestling period. No correlation between sex or age and response rate could be determined from the data collected. Different types of responses as related to sex or age did occur in 1994. Seven goshawk territories were documented, 4 in 1994 and 1 each in 1995 and 1996 . Of the 7 territories, 4 were probable breeding teritories. A response was detected at the same territory in 1994, 1995, and 1998; however, no active nest sites were found.
\end{abstract}




\section{TABLE OF CONTENTS}

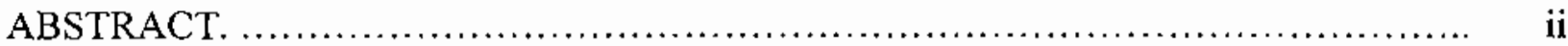

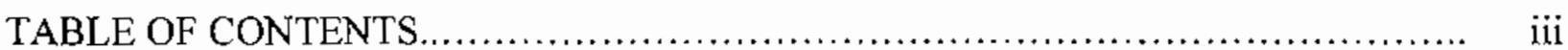

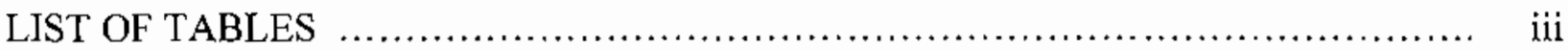

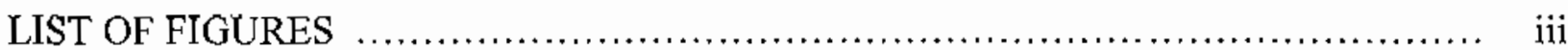

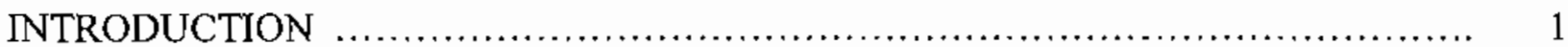

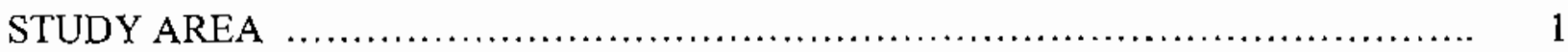

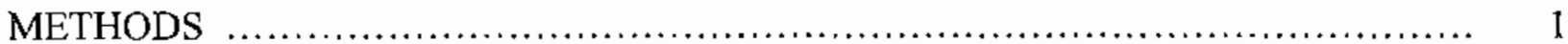

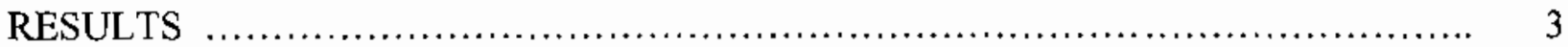

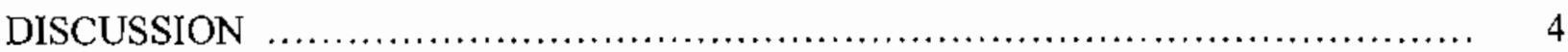

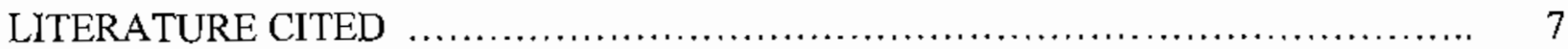

\section{LIST OF TABLES}

1. Northern goshawk sightings and responses in the St. Joe Mountains, Kootenai, Benewah, and Shoshone Counties, Idaho, 1994-1996, 1998 ..................... 8

2. Wildlife habitat types at calling stations where goshawk responses were detected in the St. Joe Mountains, Kootenai, Benewah, and Shoshone Counties, Idaho, 1994-1996, 1998

\section{LIST OF FIGURES}

1. Northern goshawk survey area on BLM lands within Benewah, Kootenai, and Shoshone Counties, Idaho

2. Complete coverage of survey areas without roads (A) and survey areas with roads and/or trails (B) 


\section{INTRODUCTION}

The Northern Goshawk (Accipiter gentilis) is frequently found in forested habitats consisting of intermediate to mature or even over-mature stands with a high degree of canopy closure (Bull and Hohmann 1994, Bright-Smith and Mannan 1994). The understory is generally open and parklike with gentle to moderately steep slopes providing a clear flight path to the nest and unobstructed hunting. These forests are subject to structural changes from timber harvests or other stand altering forces such as disease and fire which diminish suitable goshawk habitat. Therefore, identification of nesting territories and management of these areas is important to maximize the reproductive success of the goshawk (Kennedy and Stahlecker 1993).

The protocol by Woodbridge et al. (1992) identified 3 objectives to consider when planning a survey: (1) determining the presence or absence of goshawks within the project area, (2) confirming of residence in known territories, and (3) annual monitoring of occupancy and reproductive success in known territories. Our objective was to determine the presence or absence of territorial goshawks in the survey areas.

\section{STUDY AREA}

Areas surveyed for goshawks were distributed among parcels of land administered by the BLM located in Kootenai, Benewah, and Shoshone counties. Some of the areas surveyed are under consideration for a land exchange timber sale (refer to environmental assessments ID06096-12 and ID060-95-14). Surveys were conducted in potential habitat in the Rochat Peak, Twin Crags, and Masonia quadrangles (Fig. 1). Areas in the Rochat Peak quadrangle had high road densities with gradual slopes. Stands were mostly mixed conifer composed of grand fir (Abies grandis), Douglas-fir (Pseudotsuga menziesii), western larch (Larix occidentalis), and ponderosa pine (Pinus ponderosa). The area within the Twin Crags quadrangle was less accessible and had many steep, rocky slopes. The majority of surveys were conducted in the Latour Peak/Twin Crags area and in the Pine Creek drainage. Stands were composed primarily of mountain hemlock (Tsuga mertensiana), subalpine fir (Abies lasiocarpa), and Douglas-fir. Survey areas within the Masonia quadrangle had the highest density of roads and slopes, ranging from gradual to steep. The stands were mixtures of ponderosa pine/Douglas-fir, Douglas-fir/grand fir/western red cedar (Thuja plicata), and mountain hemlock/sub-alpine fir.

\section{METHODS}

We used the survey protocol from the U.S. Forest Service (USFS), Pacific Northwest region (Woodbridge et al. 1992). The basic technique was broadcasting taped goshawk vocalizations along pre-established transects. The objective was to produce an audio and/or visual response from breeding adult goshawks or their offspring. 
Suitable nesting habitat was determined prior to the establishment of transects by examining U.S. Geological Survey (USGS) topography maps along with vegetative maps of the survey areas (Keay and Garton 1978). Maps generated by geographic information system (GIS) high-lighting areas with canopy cover $>50 \%$ were also utilized. Intermediate to mature stands of forest with $>50 \%$ degree of canopy closure were selected for survey transects. Another habitat variable considered was distance to streams, since goshawks appear to be associated with them (Bull and Hohmann 1994, Hargis et al. 1994, Younk and Bechard 1994). In 1995, 1996, and 1998 , surveys were also conducted in timber sale areas and in areas considered for a land exchange. Survey transects were established only on BLM-administered lands delineated on GIS maps.

Calling stations were set at $300 \mathrm{~m}$ intervals on transects that were located $260 \mathrm{~m}$ apart. Transects were denoted by township, range, section, and transect number (e.g. T48N R1W Sec. 35 T4). Calling stations were designated by a superscript on the transect number. Unlike the methods used by Joy et al. (1994), transects were established to accomplish logical coverage of the survey area, including the use of roads and trails whenever possible (Woodbridge et al. 1992) (Fig. 2). In 1995, 1996, and 1998, primarily unroaded areas were surveyed, and topography was considered when placing calling stations. Transects were not straight lines, but stations were still at $300 \mathrm{~m}$ intervals. Joy et al. (1994) suggested surveys include 2 or more visits to an area. Transects were surveyed where responses were recorded and also in stands with typical goshawk nesting habitat characteristics (closed canopy, mature trees, open understory, etc.), even though responses had not previously been elicited.

Surveys were conducted during the nestling (June - mid July) and fledgling (mid July August) periods. Using this time frame reduces disturbance during the courtship and nest construction periods, and maximizes response rates (Kennedy and Stahlecker 1993). The adult goshawk "alarm" call was used from early June to mid-July. The juvenile "wail" call was used from mid-July into August. All surveys were conducted between 0800 and 1730 hours. Prior to conducting the surveys, the observer was trained in northern goshawk identification by sight and sound. Survey techniques were demonstrated to insure familiarity with survey equipment and procedures.

At each calling station, the proper call was played by a Sony Walkman cassette player (model WMA53) through a Radio Shack Power hom (model 32-2037) 6 times. The first broadcast was a $60^{\circ}$ turn from the direction of travel. The call lasted 10 seconds followed by a 30 -second pause. The next 2 tums were $120^{\circ}$ in the same direction followed by 30 -second pauses. The procedure was repeated once. Surveys were halted during periods of inclement weather (high winds, heavy rain) and during periods of loud disturbance due to automobile or aircraft traffic.

Data were recorded on standardized Forest Service goshawk survey protocol forms. Sex and age of goshawks were determined when possible. Goshawks were tracked for short distances following visual responses. Nest search forms were completed regardless of search outcome. 


\section{RESULTS}

1994: Two hundred thirty-eight calling stations were completed between 6 June and 1 August. Fourteen individual goshawk responses were recorded at 9 different calling stations (Table 1). Four of the 9 calling stations had 2 birds responding (Table 1). Responses to the observer ranged from strictly audio with no visual detection, to only audio responses followed by visual detection. An audio response occurred in all 14 goshawk responses. Five goshawk responses were audio/visual while 9 were audio (Table 1).

Six nest searches were conducted following visual detections of adult and juvenile goshawks. No nests were located during these surveys. Goshawk responses were detected at 2 calling stations more than once. Also, 2 goshawks responding at the same time were recorded at 4 calling stations. The age of the responding goshawk was identifiable in all but 2 of 14 detections (Table 1). More detections occurred during the nestling period (12 responses, 153 stations) versus the fledgling period ( 2 responses, 85 stations) (Table 1 ).

Douglas-fir was present in 6 of the 8 stands where goshawks were detected (Table 2). Western larch was present in 2 stands, while mountain hemlock and ponderosa pine occurred in 1 stand each (Table 2). One stand was composed of westem red cedar and westem hemlock (Tsuga heterophylla). All stands were intermediate to mature growth with some degree of canopy closure. Although no nests were located, we believed the nesting territories were located in Douglas-fïr stands.

1995: Three hundred forty-three calling stations were surveyed between 8 June and 14 August. Four individual goshawk responses were recorded at 3 different calling stations (Table 1). One of the 3 stations had 2 responding goshawks (Table 1). Three of the 4 goshawks were detected by audio/visual responses. The fourth and last goshawk detected, the only observation during the fledgling period, was only detected visually. One hundred ninety-seven calling stations were surveyed during the nestling period and 146 during the fledgling period. Ninety stations surveyed during the nestling period were areas within a land exchange project, 73 were in a timber sale area, and 34 were general surveys in previously determined suitable nesting habitat. All 146 stations surveyed during the fledgling period were in previously determined suitable nesting habitat.

1996: Two hundred seventy-four calling stations were surveyed between 6 June and 2 August. One response was recorded just northeast of the Twin Crags lookout (Table 1). This individual was detected visually and did not vocalize. Detection occurred during the fledgling period. 
On 2 separate occasions we observed goshawks while en route to survey locations. The first observation was on 30 July when a goshawk soared from ridge to ridge, crossing Latour Creek road $0.8 \mathrm{~km}$ north of the Rochat Peak/Twin Crags road junction. On August 1st, a goshawk was observed on the west side of Latour Peak flying east along the ridge toward Twin Crags. The bird appeared to be hunting and was observed twice. Open areas of grass and rock along the ridge tops support abundant prey species and therefore provide excellent hunting grounds for goshawks and other raptors. It is possible that the goshawk detected at a nearby calling station and the goshawk observed in the area are the same bird. The flying distance between the Latour Creek road and the Latour Peak/Twin Crags area is approximately $4.8 \mathrm{~km}$.

Two hundred six calling stations were surveyed during the nestling period and 68 during the fledgling period. All land exchange and proposed timber sale areas were surveyed during the nestling period (119 calling stations, covering approximately 738 hectares). In the general survey area, approximately 1,822 hectares were surveyed.

1998: One hundred sixty-eight calling stations were surveyed between 4 June and 6 August. Ninety-eight of the calling stations were surveyed during the nestling period and 70 during the fledgling period. The one response recorded during the nestling period ( 9 June) was on the Hunter/Trapper road off of the East Fork of Pine Creek (Table 1). This was a historical territory that was first found in 1994 and again in 1995 and 1998. The goshawk responded to the "alarm" call twice and then retreated into the forest. A nest search was conducted, but it was not found and the goshawk was never seen. In past surveys both adult birds had been seen (Table 1). There was no response during a subsequent survey of the territory during the fledgling period (15 July). The stand consisted of Douglas-fir/western larch intermediate-sized trees (Table 2) and a somewhat cluttered understory of shrubs and blow-down. Slope was between 20-25\%, with an eastern aspect, and a stream was approximately $600 \mathrm{~m}$ away.

\section{DISCUSSION}

No differences in response rates between adult males and females could be shown from the data collected. In 1994, possible differences existed in the type of response elicited between sexes. During the nestling period males tended to respond from longer distances than females. This may be due in part because males have a much larger home range than females (Woodbridge et al. 1992, Kennedy et al. 1994). Females tended to respond for greater periods of time and in a more aggressive manner (Woodbridge et al. 1992, Joy et al. 1994). This is likely a result of the female not wishing to leave the nest while the unfledged young were still present. One observation of an adult female making a silent fly-by did occur, but only after responding for several minutes from a stationary location. 
All juvenile responses were vocal. In 1994, prior to the fledgling period, 2 audio responses by juveniles were recorded (T47N R1E Sec. 12 T3(1) and T48N R1W sec. 28 T4(2); Table 1). Both vocalizations were followed by an adult alarm response. No sightings of juveniles occurred since the birds had not yet fledged and no nests were found. In all cases, the sex could not be determined without a visual detection. The 2 juveniles detected audio/visually were at the same calling station (T48N R2E Sec. $26 \mathrm{~T} 2(1)$; Table 1) during the fledgling stage. The juveniles continued to vocalize for an extended period of time. The juveniles were reluctant to leave the area even though the observer was in close proximity. The birds were likely recent fledglings and were remaining in the nest territory (Kennedy et al. 1994).

More responses were detected during the nestling stage with the "alarm" call than during the fledgling stage with the "wail" call during the 1994 and 1995 fieldwork. The larger number of stations surveyed during the nestling period in both years may explain this difference. The greater response rate during the nestling stage in 1995 occurred despite land exchange and timber sale areas, which were typically unsuitable nesting habitat. The greatest number of responses, $62 \%$, occurred in stands dominated by Douglas-fir (Table 2). This may be a result of the amount of canopy closure within these stands and their overall maturity. Several stands surveyed in 1996 contained mature trees and had adequate canopy closure however; Douglas-fir was present in small amounts or absent altogether.

The primary tree species in many of the survey stands were mountain hemlock and subalpine fir. Morphologically these tree species do not provide an appropriate branching structure for supporting goshawk nests. Although some branches extend horizontally from the bole, most of the branches slope downward, thus precluding large nest structures from being positioned there. Stands of predominantly mountain hemlock and sub-alpine fir may not provide suitable goshawk nesting habitat.

Responses of other raptors were recorded when they occurred. Red-tailed hawks (Buteo jamaicensis), Cooper's hawks (Accipiter cooperii), sharp-shinned hawks (Accipiter striatus), and Barred owls (Strix varia) were identified. The incident rate was not high enough to make any correlation between broadcast goshawk vocalizations and the response of other raptors in terms of sex and/or age.

The Woodbridge et al. (1992) method proved to be an effective technique to locate northern goshawks. However, to conduct goshawk surveys and nest searches more effectively, we would recommend that more than 1 surveyor be used. Having only 1 surveyor limited the amount of area that could be surveyed. Although the area to be surveyed for this project was more than 50 percent completed in 1995 (easy areas were completed first, difficult areas were left undone), the remoteness and difficult access of the remaining area to be surveyed suggested the project was roughly 30-40 percent completed. At the conclusion of the 1996 survey season, 7080 percent of the general survey area was completed. Unsurveyed units were then evaluated using aerial photographs and judged to be highly unlikely to harbor goshawks due to steep slopes with fairly open canopies and lush undergrowth. 
The 1998 field season concluded the survey for goshawks in the St. Joe Mountains of northem Idaho. The area surveyed was approximately 14,245 ha. The only area not searched was a portion of the Latour Creek drainage in the Rochet Peak quadrangle, which amounts to less than $5 \%$ of all BLM lands in this area. Five territories were found during the 4 years of the survey. Although no nests were found, 4 of 5 sites had either a pair of goshawks defending the area or juveniles were present indicating active breeding territories. Two calling stations in 1994 (T48N R1W Sec. 28 T4(2) and T47N R1E Sec. 12 T3(1); Table 1) had both adult and juvenile audio responses during the nestling period. An adult audio response was heard from calling station (T48N R1W Sec. 28 T4(2)) on 2 separate occasions. Also in 1994, 2 adult audio vocalizations were detected at calling station T47N R2E Sec. 8 T1(1)(Table 1). A pair of goshawks were detected audio/visually at a nearby calling station in 1995 (T47N R2E Sec. 08 $\mathrm{T}^{5}$; Table 1). Although no nest was found after an extensive search, the highly aggressive behavior of the pair suggests the 2 adults were a breeding pair. This area was surveyed again in 1996 during the fledgling period. Although no response was elicited, an unsuccessful nest search was conducted in the vicinity of last year's detection. In 1998 an audio response was elicited in the same area as 1994 (T47N R2E Sec. $08 \mathrm{T1}^{1}$, Table 1). This territory had goshawks on it 2 out of 4 years surveyed (Table 1). In 1994, a visual detection of 2 juveniles at station T48N R2E Sec. $26 \mathrm{~T} 2$ (2)(Table 1) during the fledgling period indicated that a nest site may have been nearby.

During the 4 years of this survey work, 20 goshawk responses were detected from 1,023 calling stations, resulting in 0.5 responses $/ 100$ stations surveyed. This is significantly lower than the 8.0 responses/100 stations that Beals and Harris $(1994,1996)$ reported while conducting goshawk surveys on the Sawtooth National Forest in southern Idaho. The St. Joe Mountains study area may not have the most suitable forest structure, large trees and a clear understory, that are usual characteristics of goshawk habitat. Most of this area was severely burned in 1910. The remaining large stands of trees were logged for timber or cut for use by the mining industry. Additionally, this area was hit hard by an ice storn in 1996 that caused small to intermediatesized trees to fall over. These factors combine to create a forest structure generally incompatible with goshawk habitat requirements. There are probably other variables also at work that are beyond the scope of this study. 


\section{LITERATURE CITED}

Beals, J. W., and C. E. Harris. 1994. Northern goshawk surveys in the Twin Falls and Burley Ranger Districts of the Sawtooth National Forest. Unpubl. Rep., Idaho Fish and Game, Boise, ID. $17 \mathrm{pp}$.

, and ___ 1996. Northern goshawk surveys in the Twin Falls Ranger District of the Sawtooth National Forest. Unpubl. Rep., Idaho Fish and Game, Boise, ID. 21 pp.

Bull, E. L. and J. H. Hohmann. 1994. Breeding biology of northern goshawks in northeastern Oregon. Studies in Avian Biology 16:103-105.

Bright-Smith, D. J., and R. W. Mannan. 1994. Habitat use by breeding male northern goshawks in northern Arizona. Studies in Avian Biology 16:58-65.

Hargis, C. D., C. McCarthy, and R. D. Perloff. 1994. Home ranges and habitats of northern goshawks in eastern Califomia. Studies in Avian Biology 16:66-74.

Joy, S. M., R. T. Reynolds, and D. G. Leslie. 1994. Northem goshawk broadcast surveys: hawk response variables and survey costs. Studies in Avian Biology 16:24-30.

Keay, J. K., and E. O. Garton. 1978. Terrestrial wildlife habitat inventory of The Rochat study area, BLM, northern Idaho. Final Report. College of Forestry, Wildlife and Range Sciences, University of Idaho. $237 \mathrm{pp}$.

Kennedy, P. L., and D. W. Stahlecker. 1993. Responsiveness of nesting Northem Goshawks to taped broadcasts of 3 conspecific calls. J. Wildl. Manage. 57:249-257.

Kennedy, P. L., J. M. Ward, G. A. Rinker, and J. A. Gessaman. 1994. Post-fledging areas in northern goshawk home ranges. Studies in Avian Biology 16:75-82.

Scott, J. M., F. Davis, B. Csuti, R. Noss, B. Butterfield, C. Groves, H. Anderson, S. Caicco, F. D'Erchia, T. C. Edwards, Jr., J. Ulliman, and R. G. Wright. 1993. Gap analysis: A geographical approach to protection of biological diversity. Wildl. Monogr. 123. 4lpp.

Woodbridge, B., G. Silovsky, K. Austin, C. Puchy, and D. Hays. 1992. Survey protocol for Northern Goshawk on national forest lands in the Pacific Northwest region. 12pp.

Younk, J. V., and M. J. Bechard. 1994. Breeding ecology of the Northern Goshawk in highelevation aspen forests of northern Nevada. Studies in Avian Biology 16:119-121. 
Table 1. Northern goshawk sightings and responses in the St. Joe Mountains, Kootenai, Benewah, Shoshone Counties, Idaho, 1994-1996 and 1998.

\begin{tabular}{|c|c|c|c|c|}
\hline Date & Transect & Response & Age & Sex \\
\hline $6 / 8 / 94$ & T48N R1W Sec. $35[$ T4 (1)] & A/V & A & M \\
\hline $6 / 15 / 94$ & T48N RlW Sec. $34[\mathrm{~T} 1(1 \& 2)]^{\mathrm{a}}$ & $\mathrm{A} / \mathrm{V}$ & A & $\mathrm{F}$ \\
\hline $6 / 16 / 94$ & T48N R1W Sec. $33[\mathrm{~T} 3(2)]^{\mathrm{a}}$ & $\mathrm{A} / \mathrm{V}$ & A & $\mathrm{U}$ \\
\hline $6 / 20 / 94$ & T48N R1W Sec. $28[\mathrm{~T} 4(2)]^{\mathrm{a}}$ & $\mathrm{A}$ & $U$ & $\mathrm{U}$ \\
\hline $6 / 21 / 94$ & T48N R1W Sec. $28[\text { T4 (2)] }]^{a}$ & A & A & $\mathrm{U}$ \\
\hline $7 / 6 / 94$ & T48N R1W Sec. $28[$ T4 (2)] & $\mathrm{A}$ & A & $\mathrm{U}$ \\
\hline $7 / 6 / 94$ & T48N R1W Sec. $28[\mathrm{~T} 4(2)]^{a}$ & A & $\mathrm{J}$ & $\mathrm{U}$ \\
\hline $7 / 6 / 94$ & T47N R1E Sec. 12 [T3 (1)] & A & A & $\mathrm{U}$ \\
\hline $7 / 6 / 94$ & T47N R1E Sec. $12[\mathrm{~T} 3(1)]$ & $\mathrm{A}$ & $\mathrm{J}$ & $\mathrm{U}$ \\
\hline $7 / 11 / 94$ & T47N RIE Sec. $08[\mathrm{~T} 1(3)]$ & $\mathrm{A}$ & $\mathrm{U}$ & $\mathrm{U}$ \\
\hline $7 / 14 / 94$ & T47N R2E Sec. $08[\mathrm{~T} 1(1)]$ & $\mathrm{A}$ & A & M \\
\hline $7 / 14 / 94$ & T47N R2E Sec. $08[\mathrm{~T} 1(1)]$ & $\mathrm{A}$ & A & $\mathrm{F}$ \\
\hline $7 / 27 / 94$ & T48N R2E Sec. $26[\mathrm{~T} 2(1)]$ & $\mathrm{A} / \mathrm{V}$ & $\mathrm{J}$ & $\mathrm{U}$ \\
\hline $7 / 27 / 94$ & T48N R2E Sec. $26[$ T2 (1)] & $\mathrm{A} / \mathrm{V}$ & $\mathrm{J}$ & $\mathrm{U}$ \\
\hline $7 / 13 / 95$ & T47N R2E Sec. 09 [T3 (5)] & $\mathrm{A} / \mathrm{V}$ & A & $\mathrm{U}$ \\
\hline $7 / 14 / 95$ & T47N R2E Sec. 08 [T4 (5)] & $\mathrm{A} / \mathrm{V}$ & A & M \\
\hline $7 / 14 / 95$ & T47N R2E Sec. 08 [T4 (5)] & $\mathrm{A} / \mathrm{V}$ & A & $\mathrm{F}$ \\
\hline $8 / 4 / 95$ & T47N R2E Sec. $24[$ T16 (4)] & $\mathrm{V}$ & $\mathrm{A}$ & $\mathrm{U}$ \\
\hline $7 / 15 / 96$ & T47N R1E Sec. 08 [T10 (2)] & $\mathrm{V}$ & $\mathrm{A}$ & $\mathrm{F}$ \\
\hline $6 / 9 / 98$ & T47N R2E Sec. 08 [T1 (1)] & $A$ & $\mathrm{U}$ & $\mathrm{U}$ \\
\hline
\end{tabular}

${ }^{\bar{x}}$ Transects located on state lands adjacent to BLM lands. Note: brackets denote transects and station number. 
Table 2. Wildlife habitat types at calling stations where goshawk responses were detected in the St. Joe Mountains, Kootenai, Benewah, Shoshone Counties, Idaho, 1994-1996 and 1998.

\section{Calling Station Habitat Type ${ }^{2}$}

T48N R1W Sec. 28 [T4 (2)]

T48N R1W Sec. 33 [T3 (2)]

T48N RIW Sec. 34 [T1 (1)]

T48N R1W Sec. 35 [T4 (1)]

T47N R1E Sec. 08 [T1 (3)]

T47N R1E Sec. 12 [T3 (1)]

T48N R2E Sec. 26 [T2 (1)]

T47N R2E Sec. 08 [T1 (1)]

T47N R2E Sec. 09 [T3 (5)]

T47N R2E Sec. 08 [T4 (5)]

T47N R2E Sec. 24 [T16(4)]

T47N R2E Sec. 08 [T10(2)]

T47N R2E Sec. 08 [T1 (1)]
Douglas-fir

western red-cedar/westem hemlock

ponderosa pine/Douglas-fir

Douglas-fir

mountain hemlock

Douglas-fir/western larch

Douglas-fir

Douglas-fir/western larch

western red-cedar/western hemlock

grand fir

Douglas-fir

mountain hemlock

Douglas-fir/western larch

a Wildife habitat types as defined by Scott et al. 1993. 


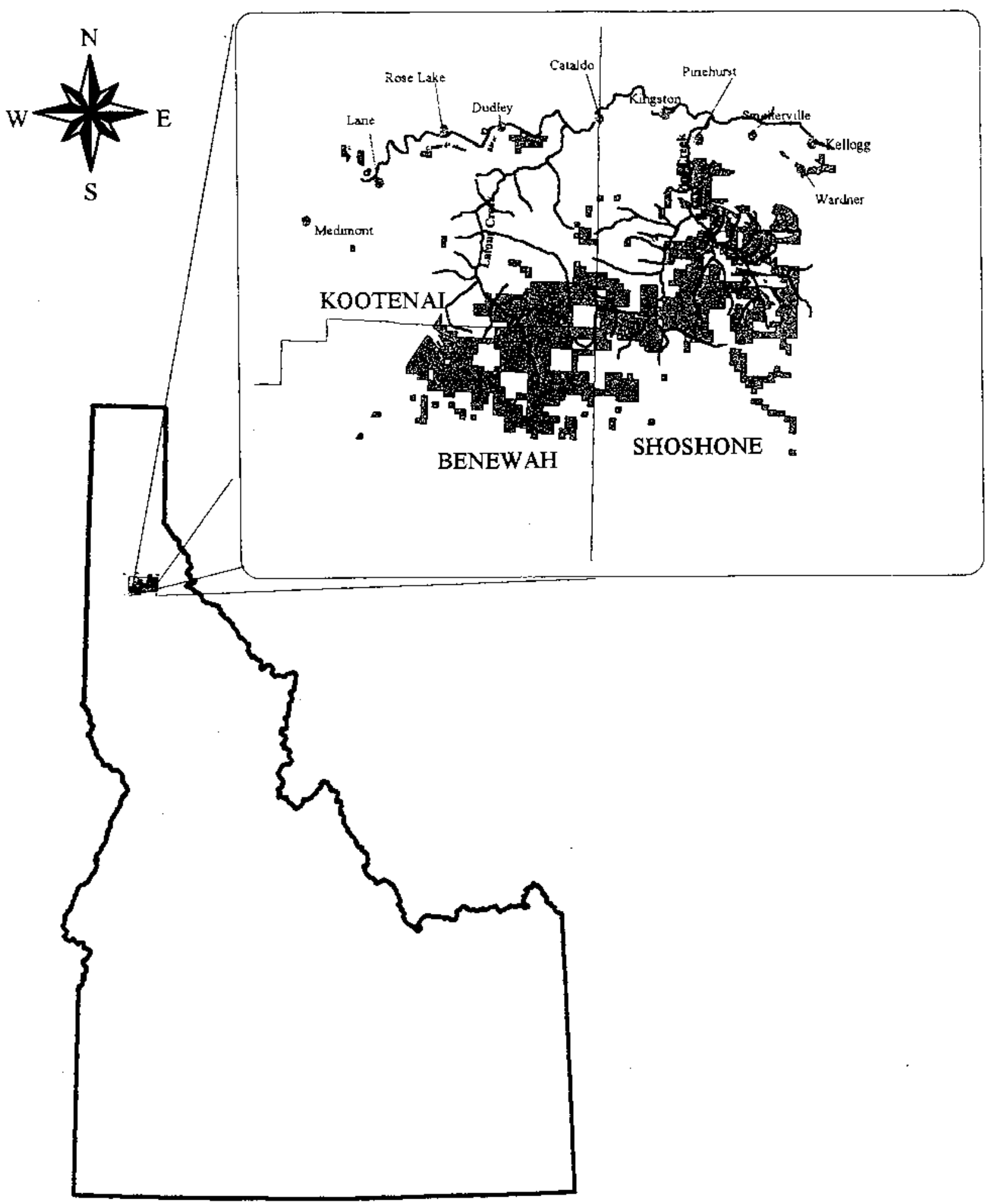

Fig. 1. Northern goshawk survey area on BLM lands located within Benewah. Kootenai and Shoshone Counties, Idaho. 

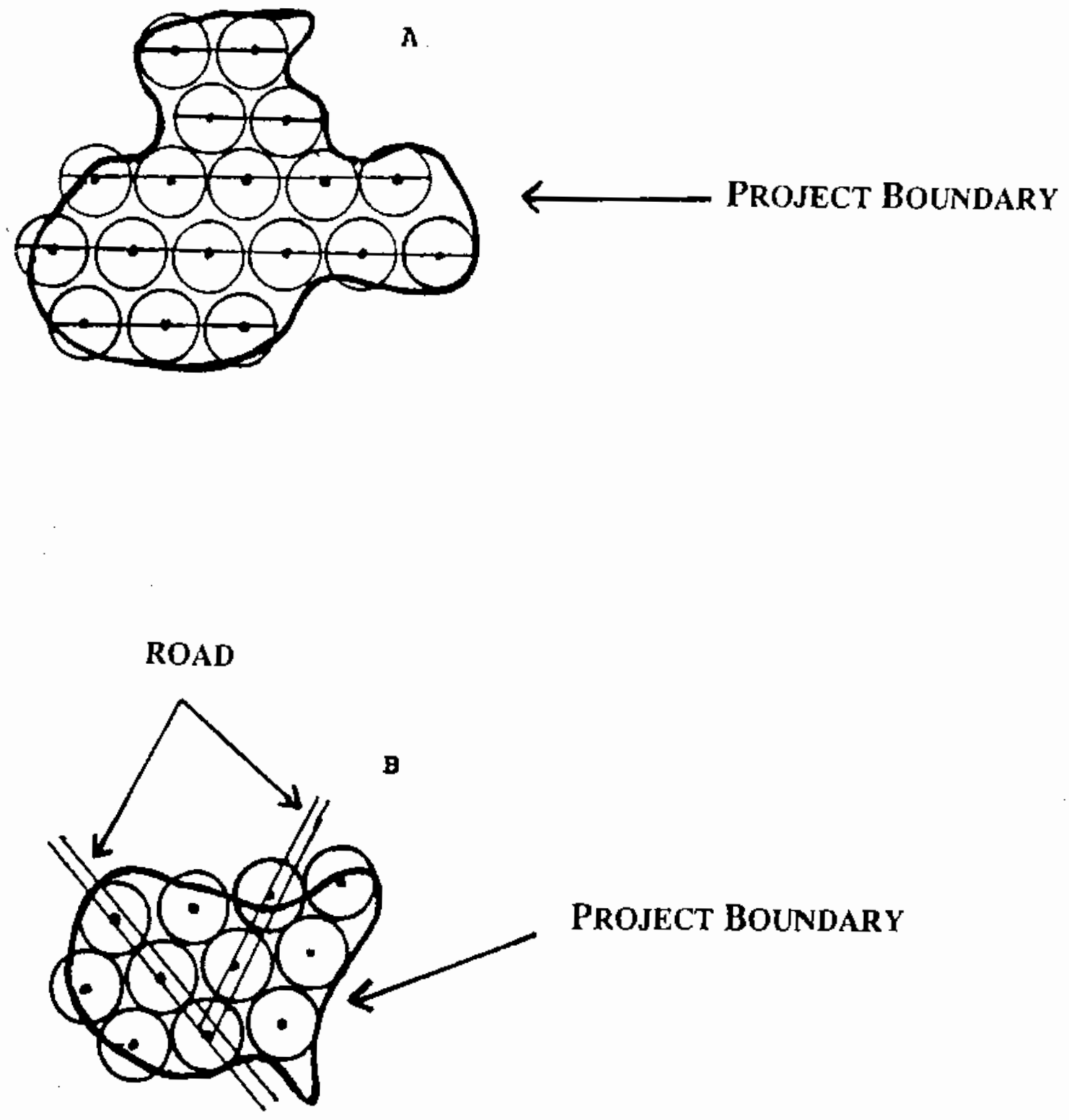

Fig. 2. Complete coverage of survey areas without roads (A), and survey areas with roads and/or trails (B). Adapted from Woodbridge et a1. (1992). 


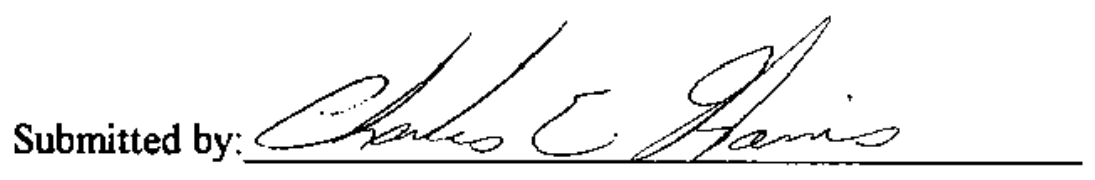

Approved by:

IDAHO DEPARTMENT OF FISH AND GAME

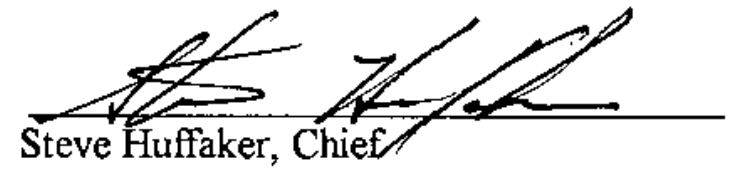

Bureau of Wildlife

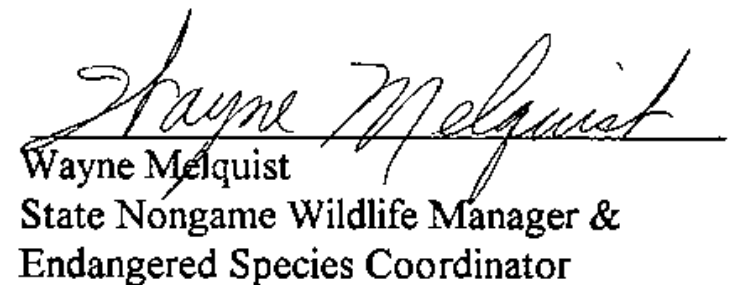




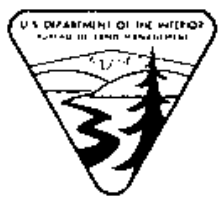

Bureau of Land Management

Idaho State Office

1387 S. Vinnell Way

Boise, Idaho 83709

BLM/ID/PT-99/007+1150 